Revista Diálogos do Direito http://ojs.cesuca.edu.br/index.php/dialogosdodireito/index

ISSN 2316-2112
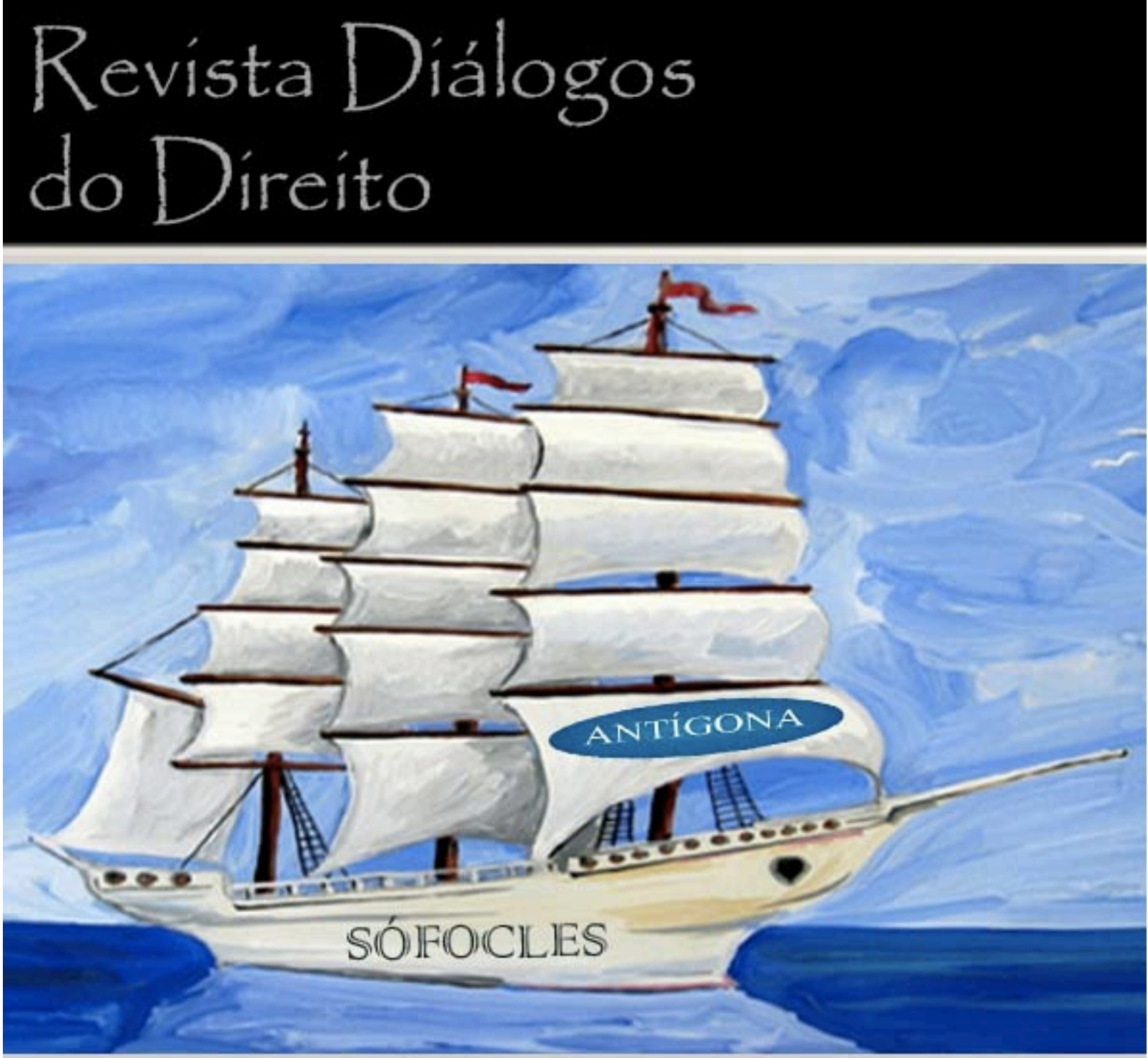

Curso de Direito $\mathrm{V}^{0} 5, \mathbb{N}^{0} 8(2015 / 1)$ ISSN 2316-2112

\title{
cestrea
}

DOI: http://dx.doi.org/10.17793/rdd.v5i8 
Revista Diálogos do Direito

http://ojs.cesuca.edu.br/index.php/dialogosdodireito/index

ISSN 2316-2112

\section{Informações Catalográficas}

Revista Diálogos do Direito- v.5, n.8 - Cachoeirinha: CESUCA

Faculdade Inedi, Direção de Pesquisa, jul./ 2015 -

Semestral.

ISSN 2316-2112

1. Direito - Literatura -. I. CESUCA Faculdade Inedi, Cachoeirinha, RS.

CDU: $34: 82-4$

Editor-Chefe

1. Dra. Angela KRETSCHMANN, CESUCA - Cachoeirinha, RS, Brasil

\section{EDITORES ASSISTENTES}

1. Dra. Jaqueline Mielke SILVA, IMED - INSTITUTO MERIDIONAL, PASSO FUNDO, RS, BR

2. Me. Renato SELAYARAM, CESUCA, Brasil

3. Dr. Guilherme De Oliveira FELDENS, CESUCA - FACULDADE INEDI, RS, BR, Brasil

4. Dr. Leonel Pires OHLWEILER, UNILASALLE - CENTRO UNIVERSITÁRIO LA SALLE, RS, BR

\section{CONSELHO EDITORIAL}

1. Dr. André Karam TRINDADE, IMED - INSTITUTO MERIDIONAL, PASSO FUNDO, RS, BR, Brasil

2. Dra. Angela KRETSCHMANN, CESUCA - RS., Brasil

3. Dr. Celso Augusto Nunes da Conceição, CESUCA - FACULDADE INEDI, RS, BR, Brasil

4. Dra. Karin Grau KUNTZ, Coordenadora Acadêmica do IBPI - Instituto Brasileiro de Propriedade Intelectual, Alemanha

5. Dra. Jaqueline Mielke SILVA, IMED - INSTITUTO MERIDIONAL, PASSO FUNDO, RS, BR

6. Dr. José Calvo González, Universidade de Málaga, Espanha, ES, Espanha

7. Dr. José de Oliveira ASCENSÃO, Universidade de Coimbra, Portugal, Portugal

8. Dr. Leonel Pires OHLWEILER, UNILASALLE - CENTRO UNIVERSITÁRIO LA SALLE, RS, BR

9. Dr. Marcos WACHOWICZ, UNIVERSIDADE FEDERAL Do PARANÁ - UFPR

10. Dr. Manuel David MASSENO, UNIVERSIDADE DE LISBOA; INSTITUTO POLITECNICO DE BEJA, PORTUGAL

\section{COMITÊ EDITORIAL - AVALIADORES CIENTÍFICOS DESTA EDIÇÃO}

1. Dra. Adriana Carvalho Pinto Vieira, UNESC, Brasil

2. Dr Agemir Bavaresco, PUC/RS - PONTIFÍCIA UNIVERSIDADE CATÓLICA DO RIO GRANDE DO SUL, PORTO ALEGRE, RS, BR, Brasil

3. Dr. André Karam TRINDADE, IMED - INSTITUTO MERIDIONAL, PASSO FUNDO, RS, BR, Brasil

4. Dra. Carla Eugênia Caldas BARROS, UFS - UNIVERSIDADE FEDERAL DE SERGIPE, SE, BR, Brasil

5. Dr. Draiton Gonzaga SOUZA, PUC/RS - PONTIFÍCIA UNIVERSIDADE CATÓLICA DO RIO GRANDE DO SUL, PORTO ALEGRE, RS, BR, Brasil

6. Dra. Fabiane SIMIONI, UFRGS - UNIVERSIDADE FEDERAL DO RIO GRANDE DO SUL, Porto Alegre, RS,BR, Brasil

7. Dr. Guilherme De Oliveira FELDENS, CESUCA - FACULDADE INEDI, RS, BR, Brasil

8. Dr. lelbo Markus Lobo DE SOUZA, UFS -UNIVERSIDADE FEDERAL DE SERGIPE - SE, BR, Brasil

9. Dr. Ingo Wolfgang SARLET, PUC/RS - PONTIFÍCIA UNIVERSIDADE CATÓLICA DO RIO GRANDE DO SUL, RS, BR, Brasil

10. Dra. Jaqueline Mielke SILVA, IMED - INSTITUTO MERIDIONAL, PASSO FUNDO, RS, BR 
11. Dra. Karin Grau KUNTZ, Coordenadora Acadêmica do IBPI - Instituto Brasileiro de Propriedade Intelectual, Alemanha

12. Dra. Kelly Lissandra BRUCH, UFRGS - UNIVERSIDADE FEDERAL DO RIO GRANDE DO SUL, RS, BR, Brasil

13. Dr. Manuel David MASSENO, UNIVERSIDADE DE LISBOA; INSTITUTO POLITECNICO DE BEJA, PORTUGAL

14. Dr. Marcos WACHOWICZ, UNIVERSIDADE FEDERAL Do PARANÁ - UFPR

15. Dra. Maria Lúcia Navarro BRZEZINSKI, UNILA - Universidade Federal da Integração Latino-Americana, Foz do Iguaçu, Brasil

16. Dr. Nilton Cesar da Silva FLORES, UNESA - Universidade Estácio de Sá, Rio de Janeiro, RJ, Brasil

17. Dr. Pablo RIBERI, UCC, Universidad Catolica de Córdoba, Córdoba, Argentina, Argentina

18. Dra. Paula Pinhal DE CARLOS, UNIRITTER - CENTRO UNIVERSITÁRIO RITTER DOS REIS, Canoas, RS

19. Dr. Paulo Caliendo Silveira, PUC/RS - PONTIFÍCIA UNIVERSIDADE CATÓLICA DO RIO GRANDE DO SUL, Porto Alegre, RS, BR, Brasil

20. Dr. Valério de Oliveira MAZZUOLI, UFMT - Faculdade de Direito da Universidade Federal de Mato Grosso Cuiabá, MT, Brasil

\section{EQUIPE TÉCNICA}

1. Bibliotecária Katiucia Rodrigues, CESUCA Faculdade Inedi, Brasil

2. Regina Bestetti, CESUCA, Brasil

\section{INDEXADORES :}

\section{Yribict}
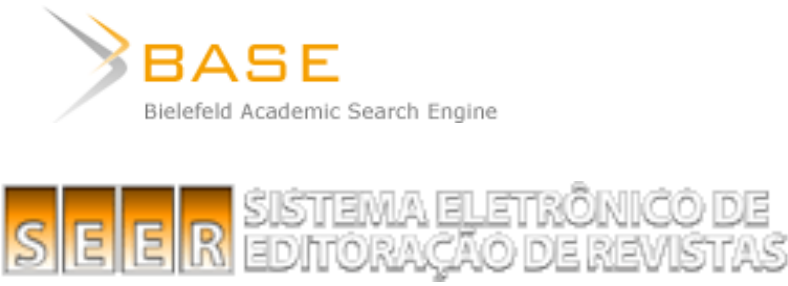

\section{Sumários.org}

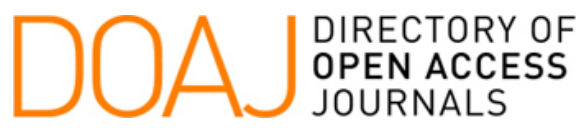

\section{(c) (1) ()}

Este trabalho foi licenciado com uma Licença Creative Commons - Atribuição - NãoComercial SemDerivados 3.0 Não Adaptada. 


\section{SUMÁRIO}

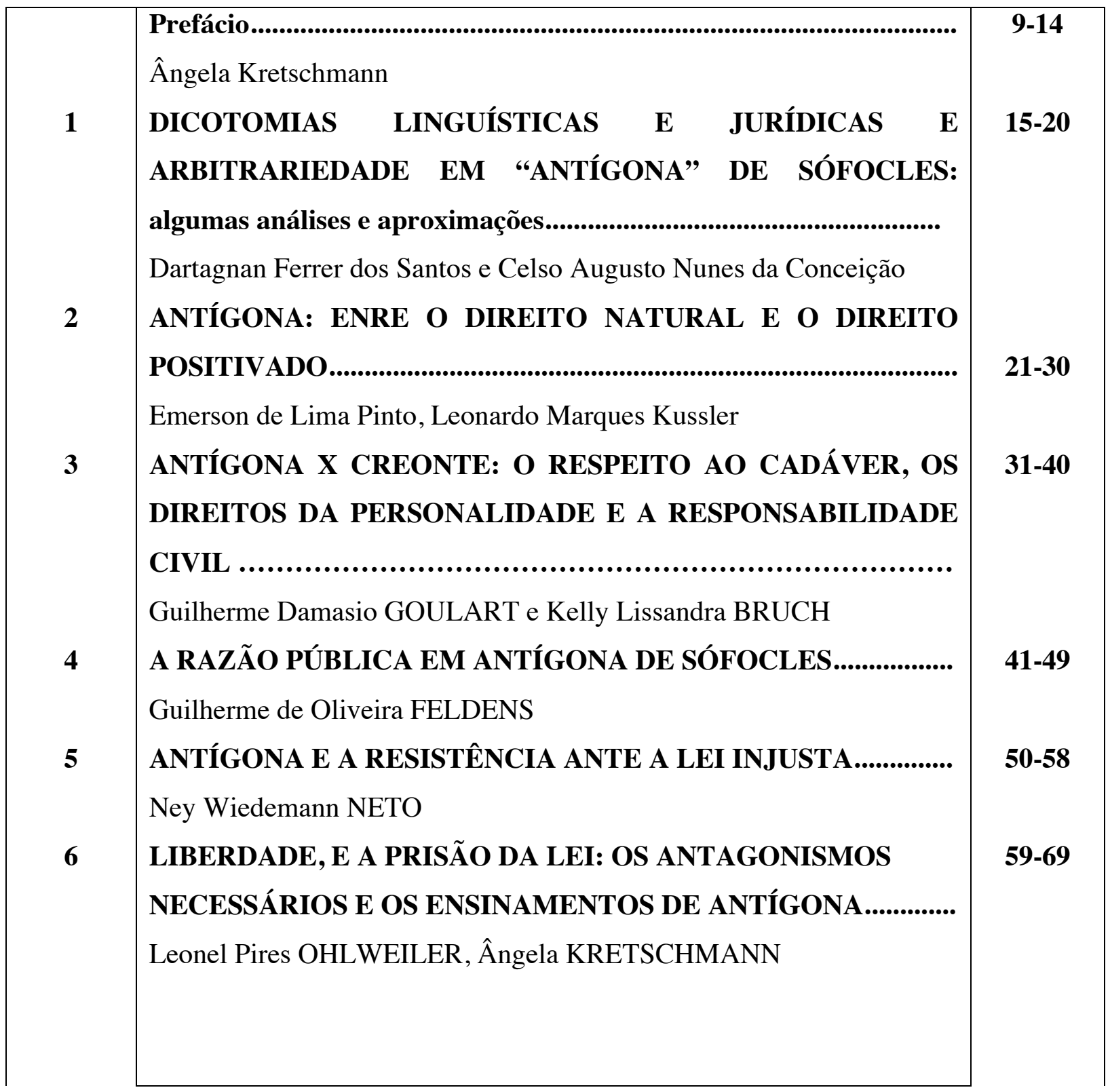

DOI http://dx.doi.org/10.17793/rdd.v5i8 


\title{
PREFÁCIO AO NÚMERO 8 (VOL.5) DA REVISTA DIÁLOGOS DO DIREITO - OBRA: ANTÍGONA, DE SÓFOCLES
}

\author{
Ângela Kretschmann ${ }^{1}$
}

O oitavo número da Revista Diálogos do Direito, chega em um momento em já torna-se lugar comum do diálogo entre professores e alunos. De acordo com o projeto inicial que deu nascimento à Revista, a inspiração do "Jardim", a cada dia, ou a cada número, reforça o espaço garantido à comunidade acadêmica para que diScutam livremente e revisitem os clássicos sempre com um olhar contemporâneo. Já não se sabe mais, como disse um professor, se é mais prazeroso descobrir um clássico pela primeira vez, ou revisitá-lo!

Sem dúvida, a edição atual, envolvendo a tragédia grega "Antígona”, de Sófocles, contou com o entusiasmo com que a obra também foi discutida nos corredores, bar, restaurante, biblioteca, trabalhos, provas, e todo tipo de atividade acadêmica em que se pôde - de uma forma ou de outra - revelar e realizar comparações acerca da lei e seus valores, atuais, com a discussão travada por Antígona e Creonte, séculos antes de Cristo.

Este diálogo, em especial, que trabalha a lei em si, é poderoso, histórico e nos força a voltar às raízes de nossas caminhadas individuais. Vivemos em permanente tensão com a lei, ora desejando-a, ora odiando-a. Um paradoxo digno de ser esclarecido, ou ao menos, digno de ser debatido na comunidade acadêmica.

Vale sempre lembrar que a forma de propor um diálogo entre Direito e Literatura nasceu com a criação do Curso de Direito do Cesuca, e essa forma de proceder tem trazido uma grande aceitação da parte da comunidade acadêmica que

\footnotetext{
${ }^{1}$ Diretora de Pesquisa (angelak@cesuca.edu.br), Doutora em Direito pela Unisinos/RS, Pós-doutora pelo Institut for Information-, Telecommunication- and Media Law (ITM), Münster, Alemanha, professora do Mestrado Profissional em Direito da Empresa e Negócios, da Unisinos. Advogada (www.kre.adv.br). 
durante um semestre não apenas elege o próximo livro para o diálogo como reflete, trabalha e prepara os artigos que serão submetidos para avaliação cega por pares, seguindo-se o processo de apreciação segundo as regras da Revista para a publicação.

É importante lembrar que a origem da Revista Diálogos vincula-se ao resultado de um Projeto de Pesquisa que iniciou com o propósito de chamar de "Jardim" o espaço, que é o lugar ou o momento em que os professores e alunos do Curso de Direito se encontram para conversar e debater uma obra literária. Esse "espaço" acabou por se tornar uma expressão do desejo de encontro e de diálogo de experiências, vivência transdisciplinar e interdisciplinar. Também partilha o convívio e aprendizagem, sendo a ideia de Jardim inspirada na proposta dos filósofos gregos do epicurismo, um lugar muito privilegiado, e raro, de liberdade. Na proposta dos estóicos, que ensinavam nos "pórticos" de Atenas, uma busca de serenidade. A proposta, mantém sua ideia original: a construção de um espaço verdadeiramente livre para o diálogo possibilitado pela escolha de obras literárias que se revestem de um instrumento, ou ao menos um convite, para o diálogo entre os pares. ${ }^{2}$

O Diálogo do número que abre o ano de 2015 inicia com o artigo dos Professores Dartagnan Ferrer dos Santos e Celso Augusto Nunes da Conceição, que utilizam a obra clássica de Sófocles para apontar algumas dicotomias linguísticas e jurídicas. Os autores enfrentam nesse desiderato linguístico, os binômios "língua versus fala", "competência versus desempenho", e no campo jurídico, as oposições "direito natural versus direito positivo", "direito universal versus direito local". Ao final, oferecem uma excelente analogia envolvendo as arbitrariedades linguística e jurídica.

Na sequência apresentamos o artigo dos Professores Emerson de Lima Pinto e Leonardo Marques Kussler. Os autores destacam que a cada nova interpretação de tragédias gregas existem novos elementos a serem considerados, em especial porque a obra clássica nunca cai em desuso, apenas se revitaliza a cada visitação. Os autores propõe uma análise da obra vinculada à interpretação de Antígona destacando-se o papel da personagem dentro de um contexto de limite da vontade individual da personagem, e o conflito com a lei do Estado, expressa pela figura de Creonte. Os

\footnotetext{
${ }^{2}$ Outros detalhes sobre o projeto que originou esta publicação podem ser encontrados no lançamento da Revista, com o seu número 1, ou mesmo no projeto de pesquisa que deu origem a esta revista, na página do Curso de Direito. 
autores apresentam o debate clássico, porém, atualizando-o para o contexto da legislação nacional.

O terceiro artigo da Revista, que apresentamos, é escrito pelos Professores Guilherme Damásio Goulart e Kelly Lissandra Bruch, intitulado, “Antígona x Creonte: o respeito ao cadáver, os direitos da personalidade e a responsabilidade civil”. Os autores analisam situações vinculadas ao Jus sepulchri, eis que chama bastante a atenção, na tragédia grega, a preocupação com o sepultamento. Os autores demonstram que tal preocupação é de extrema atualidade, e trazem a análise a teor do Código Civil brasileiro e Código de Defesa do Consumidor, que permite uma análise a partir do direito da personaldiade e da responsabilidade civil.

Já o Prof. Dr. Guilherme de Oliveira Feldens aborda a obra clássica a partir da "Razão Pública em Antígona de Sófocles”, onde foca sua análise no diálogo entre Hêmon e Creonte, que ocorre no final da tragédia. O autor ressalta assim a importância do que a filosofia moderna e pós-moderna chamam de "um debate público". Por esse viés, o autor destaca que a partir da tragédia grega de Sófocles é possível destacar um grande conflito que merece atenção: a legitimidade do poder político.

Na sequência o artigo "Antígona e a resistência ante a Lei injusta”, o Prof. Des. Ney Wiedemann Neto destaca a atualidade da tragédia grega abordando a obra através de uma visão de resistência, a resistência perante a lei injusta através da desobediência civil.

O sexto artigo da Revista, sob título "Liberdade, e a prisão da Lei: os antagonismos necessários e os ensinamentos de Antígona” aborda as diversas formas de concepção da Lei, e bem assim, as relações históricas de amor e ódio das sociedades pela Lei. O texto dos autores procura esclarecer e identificar espécies de legalismos e de uma legalidade que se mostra legítima, e chegam à Constituição Federal, observando como e porquê deve ser defendida contra quaisquer tentativas de regimes totalitários ou políticas subliminares que possam tentar fragilizá-la.

Convido os leitores para que acessem cada artigo e percebam por si a imensa riqueza e profusão de ideias possibilitada sob inspiração de Sófocles e sua obra “Antígona”. Sempre é acalentadora a constatação das diversas formas de abordagens, 
Revista Diálogos do Direito http://ojs.cesuca.edu.br/index.php/dialogosdodireito/index

ISSN 2316-2112

os diversos olhares que se concentram, pairam e contemplam uma obra clássica, e como os olhares distintos nos abrem para novas possibilidades.

\title{
Desejo uma boa leitura a todos.
}

Cachoeirinha, agosto de 2015.

\author{
Dra. Ângela Kretschmann
}

